\title{
Três movimentos metodológicos para o estudo da Biblioteca Pessoal Alda Lodi
}

\section{Three methodological movements for the study of the Personal Library Alda Lodi}

\author{
Brian Diniz Amorim ${ }^{1}$ \\ Maria Laura Magalhães Gomes ${ }^{2}$
}

\section{Resumo}

$\mathrm{O}$ artigo apresenta três movimentos metodológicos empreendidos em uma pesquisa realizada tomando como fonte e objeto a biblioteca da professora Alda Lodi. O texto é centrado na apresentação e discussão das escolhas metodológicas realizadas nos três movimentos empreendidos: o primeiro, a constituição do corpus de pesquisa através de uma catalogação dos livros da biblioteca; o segundo, uma investigação dos autores mais citados nos livros da biblioteca mediante o mapeamento das referências bibliográficas; o terceiro, a escolha de dois livros para uma análise mais aprofundada e a investigação das marcas de leitor presentes nesses livros. Destacam-se as implicações das escolhas para a pesquisa, assim como defende-se a adoção de procedimentos metodológicos adequados e posteriores ao conhecimento dos objetos de pesquisa. Por fim, ressalta-se a possibilidade do uso das marcas de leitor na compreensão dos usos do texto pelo professor-leitor.

Palavras-chave: Alda Lodi; Ensino de Matemática; Escola Nova; Bibliotecas de Professores.

\begin{abstract}
The article presents three methodological movements undertaken in a research having Alda Lodi's library as source and object. The text focus on the presentation and discussion of the methodological choices made in the three movements undertaken: the first, the constitution of the research corpus through a cataloging of the books of the library; the second, an investigation of the most quoted authors in the same books through the mapping of bibliographical references; the third, the choice of two books for a more in-depth analysis and the investigation of marks made by the reader in these books. We highlight the implications of the research choices, as well as the adoption of appropriate methodological procedures subsequent to the knowledge of the research objects. Finally, the possibility of the use of marks made by the reader for understanding the uses of the text by the teacherreader is emphasized.
\end{abstract}

Keywords: Alda Lodi; Mathematics Teaching; New School; Teachers' Libraries.

\section{Introdução: Alda Lodi e a constituição de sua biblioteca pessoal (BPAL)}

Neste estudo, pretendemos discutir possíveis movimentos metodológicos para investigações que tomem como fonte documental bibliotecas pessoais de professores, a partir de um estudo sobre as indicações metodológicas para o ensino de Matemática presentes nos livros da Biblioteca Pessoal Alda Lodi (BPAL). Pretendeu-se explorar como a professora

\footnotetext{
Submetido em: 06/12/2018 - Aceito em: 29/03/2019 - Publicado em: 30/03/2019

1 Mestre em Educação pela Universidade Federal de Minas Gerais. Brasil. Email: briandinizamorim@gmail.com.

2 Doutora em Educação pela Universidade Estadual de Campinas. Bolsista de Produtividade do CNPq. Professora do Departamento de Matemática e do Programa de Pós-Graduação em Educação da Universidade Federal de Minas Gerais, Brasil. Email: mlauramgomes@gmail.com.
} 
DOI: https://doi.org/10.20396/zet.v27i0.8654185

Alda Lodi, importante personagem da educação mineira, investiu na sua função de professora formadora e compreender como nesse investimento participaram a aquisição dos livros e a formação da sua biblioteca pessoal. Em especial, com os movimentos metodológicos que apresentaremos, buscou-se perceber como a professora e leitora Alda Lodi se apropriou das indicações metodológicas para o ensino de Matemática na sua própria prática docente. Para isso, definimos como marco temporal a primeira metade do século $\mathrm{XX}$, período em que a professora atuou diretamente na formação de professores de Matemática, uma vez que ela exerceu a regência da disciplina Metodologia da Aritmética na Escola de Aperfeiçoamento de Professores, em Minas Gerais, no período 1929-1946.

Foram realizados três movimentos metodológicos na pesquisa, que destacaremos nas próximas seções: o primeiro, a constituição do corpus de pesquisa através de uma catalogação dos livros da biblioteca; o segundo, uma investigação dos autores mais citados nos livros da biblioteca, mediante o mapeamento das referências bibliográficas; o terceiro, a escolha de dois livros para uma análise mais aprofundada e a investigação das marcas de leitor presentes nos volumes dessas obras presentes na BPAL.

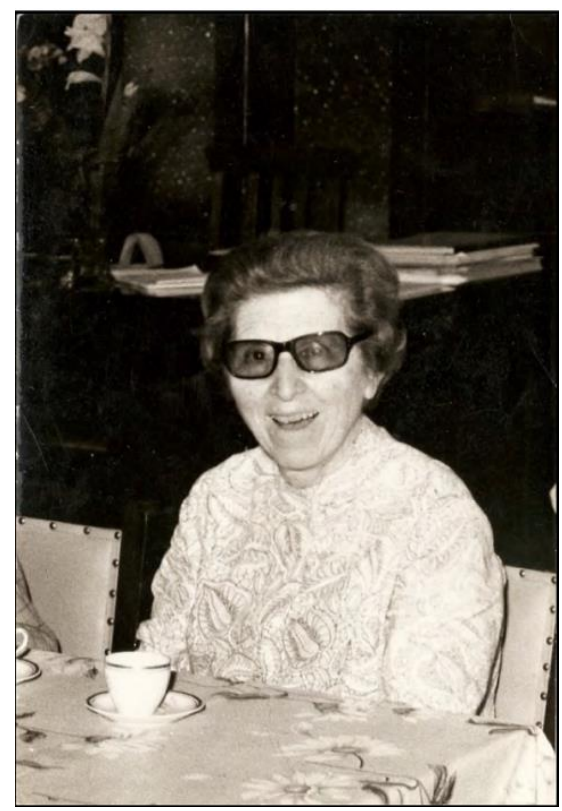

Figura 1 - Alda Lodi.

Reproduzido de Reis (2014).

Pode-se resumir a trajetória profissional da professora da seguinte forma: Alda Lodi nasceu em 17 de dezembro de 1898, em Belo Horizonte, e dedicou-se à educação em Minas Gerais durante 70 anos. Foi escolhida pelo governo mineiro como membro da comissão oficial de professores que fariam um curso de especialização no Teachers College, na Universidade de Colúmbia, nos Estados Unidos. Foi uma das fundadoras da Escola de Aperfeiçoamento, em Belo Horizonte, tendo lecionado Metodologia da Aritmética nessa instituição. Participou também da criação da Faculdade de Filosofia, Ciências e Letras de Belo Horizonte - atualmente, Faculdade de Filosofia e Ciências Humanas (FAFICH) da UFMG -, onde se aposentou e recebeu o título de professora emérita. Faleceu em 2002, aos 104 anos. 
DOI: https://doi.org/10.20396/zet.v27i0.8654185

O início da escolarização pública de Alda se deu quando ela foi matriculada tardiamente no $3^{\circ}$ grupo escolar, pois fora "alfabetizada em casa pelo irmão Euvaldo e, certamente, matriculada aos 11 anos para complementar seus estudos primários" (Fonseca, 2010, p. 56). Ela concluiu os estudos primários em 1912, ano em que ingressou no curso normal.

Os arquivos do período em que Alda Lodi foi normalista, entre 1912 e 1915, registrados no Livro de Matriculas do Arquivo Geral do IEMG (Instituto de Educação de Minas Gerais), apresentam, como avaliação de seu desempenho nas disciplinas cursadas, conceitos como "distinção, plena e plenamente", com destaque para as disciplinas de Aritmética, Geometria e Música. Isso corrobora a ideia de que ela já investia na sua formação, sendo responsável e dedicada aos seus estudos.

Alda Lodi formou-se normalista no final do ano de 1915, tendo iniciado a carreira docente em 1916, no Grupo Escolar anexo à Escola Normal Modelo, como professora contratada. Fonseca (2010) observa que, na época, era natural que a profissão de professores primários fosse, majoritariamente, ocupada por mulheres.

As cartas trocadas com familiares, em especial com o irmão Euvaldo Lodi, revelam um envolvimento contínuo dos familiares com a carreira da professora e de sua irmã Yolanda, bem como o bom trânsito político da família no governo mineiro. Essa facilidade, conforme Fonseca (2010), seria a forma usual para galgar, naquela época, degraus no serviço público. Em especial, o irmão de Alda a aconselhava a se empenhar para evoluir no magistério. Sobre uma das correspondências do irmão, Fonseca (2010) indica que "os termos dessa carta me fazem pensar sobre as questões políticas envolvidas na carreira de Alda Lodi, desde o início, uma vez que, a possibilidade de uma professora primária procurar o Presidente do Estado, ou seu secretário, para tratar de sua carreira, não se abria para qualquer pessoa (p. 64)". Em outra carta, o irmão Jurandir diz que "o facto mais importante para mim é o estudo da Alda" (Fonseca, 2010, p. 65), o que reforça a preocupação familiar com o desenvolvimento profissional da professora.

Em 1925, Alda Lodi foi nomeada pelo presidente do Estado de Minas Gerais, Fernando de Mello Vianna, como professora da primeira escola mista anexa à Escola Normal Modelo. Ela permaneceu nessa condição até que, em agosto de 1927, foi enviada para o instituto internacional do Teachers College, da Universidade de Columbia.

O envio de uma comissão de cinco professoras ${ }^{3}$ para cursar uma especialização no Instituto Internacional do Teachers College teve por objetivo a preparação de docentes para lecionar na Escola de Aperfeiçoamento de Professores, em Belo Horizonte. Discorremos, a seguir, sobre o contexto em que essa instituição foi criada.

Durante os anos de 1927-1928, ocorreu em Minas Gerais um programa de renovação escolar, através de um conjunto de ações governamentais, com a implementação de várias

\footnotetext{
3 As professoras Alda Lodi, Amélia de Castro Monteiro, Benedicta Valladares Ribeiro, Ignácia Ferreira Guimarães e Lúcia Schmidt Monteiro de Castro.
} 
DOI: https://doi.org/10.20396/zet.v27i0.8654185

mudanças no ensino primário. A "Reforma Educacional Francisco Campos e Mário Casasanta", nome que se associou a esse conjunto de ações, era composta de diversos decretos que, além de modernizar o ensino primário, versavam sobre o ensino normal, modificando também a formação inicial dos professores nas escolas normais. O novo modelo para a educação intencionado pelo governo mineiro tinha como princípios aqueles propagados por autores do movimento da Escola Nova, amplamente difundidos no Brasil daquele momento. Assim, o secretário de Negócios do Interior, Francisco Campos, em vários de seus textos, referia-se a uma série de autores filiados ao movimento escolanovista, tais como John Dewey, Ovide Decroly, William Kilpatrick e Édouard Claparède (Peixoto, 2003).

A Escola Nova, proposta pelos reformistas, também chamada de "Escola Ativa", "Escola Moderna", "Escola Progressista" e "Escola do Trabalho", segundo Veiga (2007), foi um movimento pedagógico iniciado na última década do século XIX que buscava renovar a pedagogia e a prática escolar. Apesar de ter especificidades na adoção em diferentes países, e por diferentes autores, a autora destaca que esse movimento pode ser sintetizado pela defesa de sete temas básicos: "puerismo (procedimentos didáticos centrados na criança); ênfase na aprendizagem pela atividade; motivação; estudo a partir do ambiente circundante; socialização; antiautoritarismo (crítica a imposições) e anti-intelectualismo (crítica ao verbalismo de muitos programas de ensino)" (Veiga, 2007, p. 217).

Em seu esforço para consolidar o conjunto de ações das reformas, até mesmo para materializar as ideias de que o Estado deveria investir na formação de professores, o governo criou, via decreto de 22 de fevereiro de 1929, a Escola de Aperfeiçoamento de Professores, para oferecer cursos que preparassem os docentes para a aplicação das propostas renovadoras. Fonseca (2010) narra que a inauguração da Escola ocorreu em 14 de março de 1929 e informa que ela foi extinta em 26 de janeiro de 1946, pelo decreto 1666, sendo então completamente incorporada ao Curso de Administração Escolar, a ser oferecido pelo recéminaugurado Instituto de Educação de Minas Gerais (IEMG).

Reis (2014) e Fonseca (2010) sublinham que a ida de Alda Lodi para o Teachers College foi um marco importante para sua carreira profissional, projetando-a tanto no magistério quanto nas funções administrativas. Um dos aspectos realçados por Reis (2014), como importante na escolha do nome de Alda para a comissão enviada aos Estados Unidos é o bom trabalho realizado por ela com os alunos "atrasadíssimos". A professora é descrita como muito dedicada à profissão.

Ela permaneceu no Teachers College no período de 1927 a 1929 e, no retorno ao Brasil, foi a responsável pela disciplina Metodologia da Aritmética, na Escola de Aperfeiçoamento de Professores, onde atuou até o fechamento da instituição. Posteriormente, foi professora do curso de Administração Escolar, no Instituto de Educação de Minas Gerais (IEMG).

Este breve relato da trajetória profissional de Alda Lodi nos permite pensar sobre as condições que favoreceram a sua progressão profissional, assim como a constituição de sua biblioteca pessoal. A professora, nos diversos espaços de formação e atuação profissional, 
DOI: https://doi.org/10.20396/zet.v27i0.8654185

mesmo nos anteriores à sua escolha para integrar a comissão enviada pelo governo mineiro ao Teachers College, da Universidade da Colúmbia, é reconhecida como dedicada à profissão e responsável para com os seus deveres. Entretanto, é marcante em sua trajetória a influência de sua origem social, já que advinha de uma família abastada e influente. Fonseca (2010) refere-se a cartas dos familiares de Alda Lodi que revelam relações com pessoas proeminentes, a exemplo de Arthur Bernardes (1875-1955), presidente do Estado de Minas Gerais (1918-1922) e da República (1922-1926). É possível que relações desse tipo tenham repercutido fortemente na escolha da professora para integrar a comissão de docentes enviada pelo governo estadual mineiro aos Estados Unidos. Do mesmo modo, adquirir as centenas de livros, em grande parte em língua estrangeira, só seria possível para alguém com condições econômicas compatíveis com tais gastos.

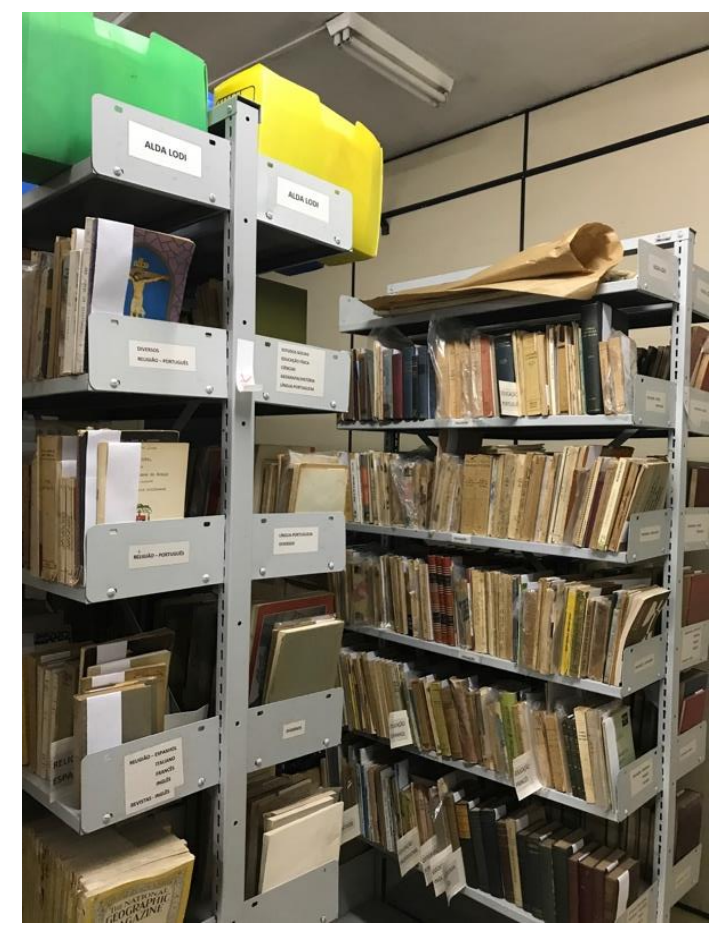

Figura 2 - A Biblioteca Pessoal Alda Lodi é formada por 3 estantes de livros.

Fonte: Autor 1 (2018).

Entendemos como Biblioteca Pessoal Alda Lodi (BPAL) o conjunto de livros hoje guardados no acervo especial dedicado à professora. A BPAL também é compreendida como um acervo temporal e histórico pois, ao longo do tempo, sofreu diversas alterações e movimentações que alteraram sua composição, organização e disponibilidade para consulta. Acreditamos que essa delimitação se faz necessária para uma boa caracterização de nossa fonte de pesquisa, assim como para qualquer pesquisa de natureza documental. $\mathrm{O}$ acervo de Alda Lodi está alocado em 3 estantes, ocupando 30 prateleiras, que reúnem 1204 livros $^{4}$.

Com um conjunto de mais de mil livros, precisávamos pensar em um modo para

\footnotetext{
${ }^{4}$ Dado obtido junto ao responsável pela biblioteca que, gentilmente, compartilhou conosco a planilha com o levantamento do acervo, elaborada por funcionários da Biblioteca Bartolomeu de Queirós, órgão do governo mineiro responsável pela guarda e conservação dos livros da BPAL.
} 
DOI: https://doi.org/10.20396/zet.v27i0.8654185

estudar esses documentos, selecionando os que comporiam a nossa investigação. O fato é que optamos por não decidir a metodologia de pesquisa a priori, criando nossos movimentos metodológicos a partir do conhecimento que estabelecemos gradativamente com o nosso objeto, a biblioteca de Alda Lodi, e buscando um tratamento adequado a ele, de forma a responder à nossa questão de pesquisa. Nesse sentido, adotamos o entendimento de Garnica (2015):

sempre entendemos metodologia não como um mero conjunto de procedimentos, mas como um complexo que exige também a fundamentação desses procedimentos. Nunca se buscou apenas como fazer, mas por que fazer de determinado modo. Além disso, entendeu-se, desde o princípio, que metodologia não é algo estático, mas um arsenal de possibilidades, sempre em construção. Disso surge a ideia de que metodologia é, sempre, uma trajetória, ou seja, de que o pensar metodológico não se dá despregado do objeto a ser estudado e que, portanto, as tramas e justificações de como e por que fazer ocorrem ao mesmo tempo em que determinadas pesquisas são feitas (p. 38, grifos do autor).

Julgamos que o relato dos movimentos que realizamos pode auxiliar investigações que envolvem bibliotecas, mas não tivemos a intenção de formular uma súmula de procedimentos com amarras para as pesquisas que tomem como fonte e/ou objeto as bibliotecas de professores. Avaliamos que o pesquisador deve, em cada caso, ponderar os procedimentos mais adequados ao seu objeto de estudo, podendo, em algumas situações, adotar procedimentos semelhantes.

\section{Primeiro movimento: constituição do Corpus de Pesquisa}

O primeiro movimento, indispensável a nossa investigação, era a constituição do corpus de pesquisa. Tendo em vista a questão "que indicações metodológicas para o ensino de Matemática na escola primária estão presentes nos livros que circularam em Minas Gerais, na primeira metade do século XX, presentes na Biblioteca Pessoal Alda Lodi (BPAL)?" inspecionamos todos os livros da BPAL e selecionamos aqueles que, potencialmente, pudessem contribuir na obtenção de respostas a essa questão.

Nossa seleção baseou-se em dois critérios: 1) a obra deveria ter sido publicada e adquirida na primeira metade do século XX e tratar de assuntos ligados ao ensino de Matemática; 2) quando versasse sobre outros assuntos, o livro precisaria tecer algum tipo de consideração sobre o ensino de Matemática.

O primeiro critério, que diz respeito à época contemplada, está ligado ao período em que Alda Lodi atuou diretamente na formação de professores que atuariam no ensino de aritmética na Escola de Aperfeiçoamento de Professores, o que ocorreu no período 19291946.

O segundo critério traz consigo uma importante decisão metodológica e que, sem o contato com o objeto de estudo, poderia se dar de modo diverso. Pode parecer óbvio que a seleção do corpus focalizasse os livros que abordassem o ensino de Matemática. Entretanto, o estudo exploratório que fizemos nos mostrou que obras aparentemente sem nenhuma ligação com a disciplina poderiam conter considerações sobre o seu ensino. 
DOI: https://doi.org/10.20396/zet.v27i0.8654185

Para exemplificar, o livro Cinema contra Cinema: bases geraes para um esboço de organização do Cinema Educativo no Brasil ${ }^{5}$, de Joaquim Canuto Mendes de Almeida, publicado em 1931, apesar de não tratar especificamente de questões ligadas ao ensino de Matemática, foi selecionado no levantamento por contemplar uma discussão sobre o uso do cinema educativo nas diversas disciplinas, inclusive em Matemática.

Encontramos um total de 338 obras atendendo aos critérios adotados, das quais coletamos os seguintes dados:

i. relativos aos aspectos editoriais das obras: nome do(s) autor(es), título, data de publicação, número da edição, editora, idioma;

ii. relativos à materialidade do objeto: número de páginas, estado de conservação, dimensões do volume, variações tipográficas no texto, descrição da capa e da encadernação, ilustrações;

iii. relativos aos paratextos editoriais - de acordo com Genette (2009): estrutura da obra, prefácio e/ou apresentação da obra, apresentação do autor, dedicatória, citações ou críticas da imprensa; anúncios de outras obras, outros (ex: orelha);

iv. relativos ao conteúdo: público-alvo (implícito ou explícito), assunto da obra, referências bibliográficas;

v. relativos a registros feitos no volume: carimbos de livrarias ou bibliotecas, registros de aquisição, marcas de leitor.

A partir dos dados obtidos inicialmente, dois aspectos mereceram destaque.

$\mathrm{O}$ primeiro concerne à quantidade de livros selecionados por década de publicação. $\mathrm{O}$ quadro 1 apresenta essa quantificação.

Quadro 1 - Período de publicação dos livros selecionados, por década.

\begin{tabular}{|c|c|}
\hline \hline Década de Publicação & Quantidade no acervo \\
\hline \hline Década de 1910 & 10 \\
\hline Década de 1920 & 148 \\
\hline Década de 1930 & 44 \\
\hline Década de 1940 & 51 \\
\hline Sem data de publicação & 85 \\
\hline \hline TOTAL & $\mathbf{3 3 8}$ \\
\hline
\end{tabular}

Fonte: Quadro elaborado a partir dos dados contidos na tabela de catalogação dos livros da biblioteca elaborada pelos autores do artigo.

Percebemos uma grande diversidade no período de publicação das obras, dentre as décadas da primeira metade do século XX. Também é importante ressaltar que 85 livros, um quarto do total, não têm sua data de publicação registrada. Observa-se, contudo, a

\footnotetext{
${ }^{5}$ Almeida, J. C. M. de. (1931). Cinema contra Cinema: bases geraes para um esboço de organização do Cinema Educativo no Brasil. Rio de Janeiro: Companhia Editora Nacional.
} 
DOI: https://doi.org/10.20396/zet.v27i0.8654185

predominância dos livros publicados na década de 1920, em que a professora Alda Lodi integrou a comissão que foi enviada, pelo governo de Minas Gerais, para cursar uma especialização nos Estados Unidos, no Teachers College. Essa observação nos permite pensar sobre a importância, para Alda Lodi, do período em que esteve no curso de especialização para a formação da biblioteca e para a sua formação enquanto professora.

O segundo aspecto se refere ao idioma das obras presentes no acervo. Os resultados da contagem realizada são mostrados no quadro 2.

Quadro 2 - Idioma de publicação dos livros selecionados.

\begin{tabular}{|c|c|}
\hline \hline Idioma & Quantidade no acervo \\
\hline \hline Espanhol & 11 \\
\hline Francês & 34 \\
\hline Inglês & 206 \\
\hline Italiano & 6 \\
\hline Português & 81 \\
\hline \hline TOTAL & $\mathbf{3 3 8}$ \\
\hline \hline
\end{tabular}

Fonte: Quadro elaborado a partir dos dados contidos na tabela de catalogação dos livros da biblioteca elaborada pelos autores do artigo.

Imediatamente se pode notar o grande predomínio dos livros publicados em Inglês, que perfazem $61 \%$ do total. Em segundo lugar, estão os livros em Língua Portuguesa (24\% do total), o que é natural. Também encontramos livros em Italiano, Espanhol e Francês, cujo total representa $15 \%$. Como ressaltado no comentário sobre a tabela anterior, o predomínio de obras de língua inglesa indica a relevância, para a formação da biblioteca, do período em que Alda esteve nos Estados Unidos.

Sobre a aquisição das obras, podemos notar algumas informações relevantes: dos 338 livros do corpus, 154 contam com algum tipo de registro da sua forma de aquisição. Entendemos aquisição como o ato de "tornar-se proprietário de" (Houaiss et al., 2009), abarcando, nessa percepção, a compra ou o recebimento das obras como presente ou doação. Nos livros, o tipo de registro mais comum é a anotação do nome Alda Lodi, seguido da data e da cidade de aquisição na folha de rosto da obra. Há, porém, obras que não foram compradas pela própria Alda Lodi. Existem, na BPAL, livros que lhe foram presenteados por conhecidos ou antigos colegas. Verificamos, igualmente, a presença de obras com dedicatórias de seus autores a Alda Lodi, como em Desenvolvimento mental da criança ${ }^{6}$, de Helena Antipoff, e Dados de Psicologia da Criança ${ }^{7}$, de Isaías Alves.

Essas observações nos permitem problematizar a composição da BPAL: percebe-se que Alda Lodi investiu muito na sua formação para ensino de Metodologia da Aritmética na Escola de Aperfeiçoamento de Professores e que esse investimento, pelo menos no volume de

\footnotetext{
${ }^{6}$ Antipoff, H. (1939). Desenvolvimento mental da criança. Belo Horizonte: Sociedade Pestalozzi.

${ }^{7}$ Alves, I. (1944). Dados da Psicologia da Criança (conferência realizada na Faculdade Nacional de Filosofia). Rio de Janeiro. Serviço Gráfico do IBGE.
} 
DOI: https://doi.org/10.20396/zet.v27i0.8654185

livros que foi adquirido, não teria sido possível sem um considerável dispêndio de recursos financeiros da professora, o que chama a atenção para a situação socioeconômica privilegiada da professora, que permaneceu solteira durante toda a sua vida e era membro de uma família abastada de Belo Horizonte (Fonseca, 2010). Ter recebido livros como presentes, inclusive de seus autores, evidencia, também, o status social do qual a educadora gozava.

Além da exploração de caráter geral, exposta nesta seção, era necessário, também, desprender dos livros dados que subsidiassem a escolha das obras que pretendíamos analisar mais detalhadamente para nosso trabalho, haja vista que seria impossível estudar as 338 obras do corpus. O primeiro desses critérios, que apresentaremos a seguir, foi o levantamento dos autores mais citados em todas as obras da BPAL, para elencar quais seriam mais representativos.

\section{Segundo movimento: mapeamento das referências bibliográficas}

Em um segundo movimento de pesquisa, era requerida uma mobilização que nos possibilitasse verificar quais ideias educacionais mais se sobressaíam na BPAL. Nesse momento, já pensávamos que seriam as ideias escolanovistas, tendo em vista sua presença em grande número de livros publicados nos Estados Unidos, na década de 1920. Entretanto, embora houvesse uma convicção quanto a esse aspecto, deveríamos considerar que a Escola Nova foi um movimento do qual participaram autores de várias correntes de pensamento e, por isso, tal mapeamento seria relevante.

Coletamos as referências bibliográficas presentes nos 338 livros do corpus. Essas referências foram digitadas em uma planilha do software Excel $^{8}$, em que identificamos a obra da qual a recolhemos e três dados: autoria, título e editora. O objetivo dessa coleta foi que, a partir dos autores cujos nomes tivessem sido citados com maior frequência, investigássemos as suas principais obras, os seus interesses e as suas ideias. Objetivávamos, portanto, conhecer os entendimentos mais gerais presentes na BPAL, as concepções mais intrínsecas aos livros do acervo.

Vale ressaltar que não foram encontradas referências bibliográficas em todas as obras presentes na biblioteca. De fato, identificamos referências de algum tipo em apenas 97 das 338 obras do nosso universo. O trabalho de coleta foi minucioso: para cada um dos livros selecionados, procuramos referências bibliográficas em todas as páginas. A necessidade desse tipo de busca decorreu da falta de um padrão, nos livros, para a apresentação das referências bibliográficas. Uma parte das obras cita as referências em notas de rodapé; outros livros trazem as referências ao final de cada um dos seus capítulos; existem ainda aqueles que as reúnem ao final, em uma lista.

Também não há um padrão aparente para a forma como as citações foram realizadas. Cada livro traz os dados das obras que mobiliza de diferentes formas. Mesmo o nome do

\footnotetext{
${ }^{8}$ Software de planilhas eletrônicas da Microsoft. Para o trabalho, utilizamos a versão 2016, para MacOs, do suíte.
} 
DOI: https://doi.org/10.20396/zet.v27i0.8654185

autor apresenta diferenciações: em alguns casos, coloca-se o nome completo; em outros, abreviam-se os prenomes; há, ainda, casos em que só é registrado o último sobrenome. Mesmo tendo a intenção de recolher apenas os três dados mencionados para cada uma das referências, não conseguimos fazer isso de modo completo, pois às vezes falta um desses dados. Mais frequentemente, trata-se da editora pela qual cada obra citada foi publicada.

Após a inserção dessas referências no Excel, foi necessário eliminar as que haviam sido digitadas em duplicidade. Como muitas obras trazem referências em notas de rodapé ou no final de cada um dos seus capítulos, há aquelas que aparecem várias vezes em um único livro. A eliminação das referências duplicadas na planilha produzida foi realizada automaticamente pelo software ${ }^{9}$. Foi digitado, eliminando-se as duplicidades, um total de 9103 referências bibliográficas nos livros da BPAL.

Após digitadas as referências bibliográficas na planilha, foi realizada a contagem de ocorrências. Para isso, organizamos uma planilha dinâmica ${ }^{10}$ com os nomes de todos os autores e utilizamos uma fórmula de contagem de textos ${ }^{11}$.

O quadro 3 mostra os cinco autores com maior quantidade de citações em referências bibliográficas dos livros da BPAL.

Quadro 3 - Cinco autores com maior quantidade de citações nos livros da BPAL

\begin{tabular}{|c|c|}
\hline AUTORES & QUANTIDADE DE CITAÇÕES \\
\hline Thorndike, E. L. & 204 \\
\hline Dewey, J. & 109 \\
\hline Wilson, G. M. & 72 \\
\hline Monroe, W. S. & 61 \\
\hline Gates, A. I. & 58 \\
\hline
\end{tabular}

Fonte: Quadro elaborado a partir dos dados contidos na tabela de catalogação dos livros da biblioteca elaborada pelos autores do artigo.

Consultando a tabela, vemos que os dois autores com maior frequência são: Edward Lee Thorndike (1884-1949), com 204 ocorrências, e John Dewey (1859-1952), com 109 diferentes citações. Com isso, podemos inferir que as ideias escolanovistas estão fortemente presentes na BPAL, uma vez que Thorndike e Dewey estão, como dissemos anteriormente, ligados ao movimento.

O autor mais citado, Edward Lee Thorndike (1874-1949), de acordo com Santos (2006), era filho de um pastor metodista e tinha como provável carreira a mesma de seu pai. Entretanto, ao ingressar na Wesleyan University (Connecticut, Estados Unidos), afastou-se

\footnotetext{
${ }^{9}$ Utilizando o recurso "remover duplicatas", disponível na aba "Dados".

${ }^{10}$ Planilha Dinâmica é um recurso automático do Microsoft Excel que reorganiza e sintetiza automaticamente os dados. No caso da planilha utilizada, o recurso fez com que o nome de cada autor fosse apresentado em apenas uma linha da planilha.

${ }^{11}$ Foi utilizada a fórmula "Cont.se" do software Microsoft Excel.
} 
DOI: https://doi.org/10.20396/zet.v27i0.8654185

desse caminho. Segundo o relato da autora, Thorndike atribui o seu interesse pelo campo da psicologia à leitura de Principles of Psychology, de William James, que foi posteriormente seu professor e mentor.

Segundo a pesquisadora, a tese de doutorado de Thorndike, intitulada Animal Intelligence: an experimental study of the associative processes in animal, orientada por James McKeen Cattell, revolucionou os alicerces da Psicologia Animal, já que foram criados novos instrumentos metodológicos para a descrição do comportamento animal. Essa tese, juntamente com as recomendações de James Cattell, o credenciou para ingressar no Teachers College.

Santos (2006) ainda relata que, depois dos estudos com animais, Thorndike dedicouse a pesquisas com crianças, que foram submetidas a seus testes sobre as teorias educacionais que defendia, e esses estudos formaram a base da Psicologia Educacional. Ele teria mobilizado vários experimentos nesse trajeto. Entretanto, não havia consenso sobre as suas ideias, já que muitos “dos contemporâneos discordavam e procuravam apontar equívocos ou fragilidades das propostas desse pesquisador. John Dewey, Charles Judd foram alguns de seus debatedores" (Santos, 2006, p. 40).

Rabelo (2016) mostra que em especial quanto a John Dewey, um dos motivos seria justamente a divergência de ambos em relação às abordagens no campo educacional. Thorndike era mais empirista e baseava-se em experimentos com jovens e crianças, enquanto Dewey tinha uma visão mais filosófica e, ainda que aceitasse que os problemas fossem somente práticos, não concebia suas soluções dessa forma.

Com o sucesso editorial de The Thorndike Arithmetics, que ultrapassou as expectativas dos editores, sendo vendido em todo o mundo e adotado oficialmente em várias partes dos Estados Unidos, Thorndike se tornou "familiar às escolas elementares e aos lares de famílias norte-americanos comuns" (Santos, 2006, p. 33).

O segundo autor mais citado, John Dewey, de acordo com Medeiros (2013), foi um educador norte-americano que nasceu em 1859 e faleceu em 1952, aos 92 anos. Graduou-se em Filosofia pela Universidade de Vermont e doutorou-se, em 1884, com um estudo sobre a psicologia de Kant.

Foi professor de diversas universidades, dentre as quais podemos destacar a Universidade de Vermont, a Universidade da Pensilvânia, a Universidade do Michigan, a Universidade de Chicago e a Universidade de Columbia. Na Universidade de Chicago, onde iniciou os trabalhos em 1896, enquanto diretor do departamento de Pedagogia, para pôr à prova suas ideias, criou uma "escola experimental" que ficou conhecida como "Escola de Dewey”. Nessa escola, experimentavam-se hipóteses da psicologia funcional e da ética de Dewey. As ideias de Dewey, como foi dito anteriormente, ficaram conhecidas pelo nome de instrumentalismo.

Verificamos a presença, na BPAL, durante o nosso levantamento, de doze obras de autoria de John Dewey e de cinco obras de autoria de Edward Lee Thorndike. 
DOI: https://doi.org/10.20396/zet.v27i0.8654185

De modo a subsidiar nosso trabalho, os dois primeiros movimentos nos possibilitaram esmiuçar o conteúdo das obras da biblioteca de modo mais geral, a fim de investigar diversos elementos cujo estudo detalhado pudesse ajudar a compreender não somente o contexto sócio-histórico de produção das obras, mas, também, a fundamentar o entendimento das indicações metodológicas para o ensino de Matemática presentes nos livros. Realizado esse movimento, passamos à escolha de livros para uma análise aprofundada, já que não seria possível estudar analiticamente a totalidade de obras do acervo.

Cabe ressaltar que, apesar de o segundo movimento, realizado por meio de um mapeamento das referências bibliográficas, indicar que os autores mais citados nas obras da BPAL eram Thorndike e Dewey, optamos por, em um terceiro movimento, considerar outros critérios na seleção de duas obras para a análise. Uma das razões é que, como a biblioteca tem uma quantidade considerável de livros adquiridos no período em que a professora Alda Lodi esteve no Teachers College, seus professores estão, naturalmente, entre os mais citados no conjunto de livros do acervo. Entretanto, consideramos que diferentes vertentes de pensamento estavam presentes na biblioteca, haja vista as diversas obras publicadas em diversos países, em diferentes anos, por autores de distintas ideias. Destarte, era nossa intenção investigar nas obras escolhidas diferentes grupos ideológicos, ainda que seus autores não estivessem, necessariamente, incluídos dentre os autores mais citados.

Esse movimento de retorno aos primeiros dados coletados, foi ao encontro da nossa concepção de que a metodologia de pesquisa deve ser adequada posteriormente ao conhecimento das fontes. Conhecendo a biblioteca, pensamos que a escolha da segunda obra a partir da afiliação ideológica seria uma boa alternativa.

\section{Terceiro movimento: a escolha de livros para uma análise aprofundada e a investigação das marcas de leitor}

\section{Escolha de duas obras para uma análise mais aprofundada}

Como foi dito, não seria exequível estudar de forma aprofundada todas as obras do corpus. Portanto, para a nossa pesquisa das indicações metodológicas presentes nos livros da BPAL, realizamos a seleção de duas obras, com fundamento em alguns critérios. Mobilizamos o levantamento dos autores mais citados nas obras da BPAL, realizado no movimento anterior, na escolha de uma das obras, The New Methods in Arithmetic, de Edward Lee Thorndike, mas optamos por revisitar os dados levantados no primeiro movimento, a fim de confirmar a escolha da primeira obra e melhor fundamentar a escolha da segunda obra.

O primeiro critério foi que, preferencialmente, selecionaríamos livros cujos assuntos abordados estivessem diretamente ligados ao ensino de Matemática. Como explicado anteriormente, livros que abordam transversalmente a Matemática foram inicialmente destacados com o interesse de se levantar informações sobre as visões circulantes naquele contexto. Entretanto, para uma análise aprofundada e, considerando que nossa pesquisa tinha foco nas concepções acerca do ensino da Matemática, julgamos mais pertinente trabalhar 
DOI: https://doi.org/10.20396/zet.v27i0.8654185

com obras diretamente vinculadas ao ensino de Matemática.

Como segundo critério, utilizamos as marcas de leitor (Galvão \& Oliveira, 2007) presentes nos livros da professora Alda Lodi. Galvão e Oliveira (2007) consideram como marca de leitor toda forma de interação com o leitor visível no livro, a exemplo de dobras de páginas, marcações de partes dos textos, grifos, páginas arrancadas, folhas inseridas em seu interior etc. Adotamos esse entendimento que, a nosso ver, poderia contribuir para nossa compreensão quanto às interações da leitora Alda Lodi com a sua biblioteca.

174

\section{Cinema contra Cinema}

para com a Sociedade das Nações. Os trabalhos inauguraram-se com enthusiasmo.

Mussolini, no discurso de abertura solenne do Instituto, na Villa Falconieri, a 5 de novembro de 1928 , em presença do rei, dos membros do Conselho, do corpo diplomatico e de altos funccionarios do Estado, sublinhou a grande vantagem do cinematographo em relação ao livro e ao jornal : falar uma lingua comprehensivel a todos os povos da terra. Fala aos olhos. Dahi seu caracter de universalidade e as inumeras possibilidades que offerece, para uma collaboração educativa de ordem internacional.

Figura 3 - Marca de leitor encontrada na página 174, do livro Cinema contra Cinema, de Joaquim Canuto Mendes de Almeida.

Fonte: Autor 1 (2018).

Do universo de 338 livros, oitenta apresentam marcas de leitor. O tipo de marcação mais comum é o grifo de um parágrafo. Como pode ser visto na figura 3, é utilizado um traço para se assinalar um trecho de um dos parágrafos do texto. Outra marcação comum é um sinal de "v" no sumário, ou nas referências bibliográficas, para destacar seções ou capítulos do livro ou títulos de outras obras. Pensamos que essas marcas poderiam indicar os livros mais relevantes, na época, para a atuação de Alda Lodi como formadora de professores e para sua própria formação enquanto professora. A escolha das marcas de leitor como critério de seleção é justificada pela relação que uma biblioteca tem com o seu proprietário, em que a posse do livro não implica necessariamente a sua leitura. A quantidade de livros com marcas de leitor do nosso corpus, assim como os mais de mil livros da sua biblioteca, nos parece indicar que Alda Lodi desenvolveu uma leitura extensiva, com muitos interesses e diversidade de temas.

O terceiro critério adotado diz respeito à presença de algum registro da forma de aquisição da obra. Nem sempre a presença de uma obra em uma biblioteca representa afinidade de pensamento entre leitor e autor. Muitas vezes, os livros têm origem em doações ou presentes, e sequer foram escolhidos pelo proprietário da biblioteca. Assim, o registro de que a obra foi comprada por Alda Lodi nos oferece um sinal de que o seu conteúdo despertou, de algum modo, o interesse da professora. 
DOI: https://doi.org/10.20396/zet.v27i0.8654185

Por fim, buscamos, conforme um quarto critério, escolher livros que indicassem, a partir dos dados coletados, a presença de diferentes correntes do pensamento educacional circulante na época. Durante a fase de recolha de informações gerais, pareceu haver em trechos dos livros, assim como em paratextos observados durante o levantamento, uma aproximação de ideias no entorno de algumas vertentes desse pensamento e, ainda que investigar e mapear as diferentes concepções circulantes não estivesse entre os nossos objetivos, ponderamos que deveríamos considerá-las ao escolher os livros a serem analisados.

O primeiro livro selecionado foi The New Methods in Arithmetic, de Edward Lee Thorndike. Esse livro, publicado em 1926 e adquirido por Alda Lodi em 1929, traz marcas de leitor e aborda temas ligados ao ensino de Matemática. Ademais, seu autor é o mais citado nos livros da BPAL, com 204 menções nos 338 livros de nosso corpus. No cruzamento de dados com outros materiais, encontramos cinco menções ao autor na agenda que Alda Lodi usou em Nova Iorque.

O segundo livro escolhido, A aritmética na Escola Nova, de Everardo Backheuser, tem registro de aquisição de Alda Lodi em Belo Horizonte em 1933, mesmo ano em que foi publicado. Constatamos a presença de apenas uma marca de leitor no texto, assinalando um parágrafo. As outras marcas estão perto dos nomes de autores que constam de suas referências bibliográficas. A escolha desse livro foi realizada devido ao potencial de informações que pode aportar acerca das ideias brasileiras sobre o Movimento da Escola Nova e por apresentar uma perspectiva, ao menos quanto ao contexto de produção, diferente da outra obra selecionada. O livro foi publicado pela Editora Católica, do Rio de Janeiro, em 1933, e tem o potencial de nos fornecer indícios sobre o embate entre ideias escolanovistas e as concepções católicas.

Sobre esse embate, Carvalho (2004) relata que houve uma oposição às ideias escolanovistas por parte de católicos organizados. A pesquisadora afirma que eles

lançaram boletins e revistas, promoveram congressos, realizaram cursos e conferências e programaram edições, no propósito de regrar a sedução exercida pelo escolanovismo sobre o professorado. Nesse empreendimento, tiveram, talvez, mais êxito do que comumente se supõe, atingindo não somente as práticas dos professores das escolas católicas, mas também as do professorado católico nas escolas públicas. Suas estratégias de difusão de versões depuradas da nova pedagogia são o contraponto necessário para melhor se aquilatarem as práticas de seus oponentes, os pioneiros da educação nova. (Carvalho, 2004, p. 94)

De acordo com a autora, a ação dos católicos tinha a intenção de manter "o primado da religião em estratégias de conformação da sociedade brasileira" (Carvalho, 2004, p. 96). Para tanto, realizaram-se dois movimentos: um primeiro, de lançar críticas diretas às ideias escolanovistas, e um segundo, de produzir um discurso escolanovista católico. Nesse segundo movimento

a pedagogia da Escola Nova era pasteurizada num receituário pedagógico saturado de sentido religioso e as questões cruciais para a renovação dos processos e das relações pedagógicas eram neutralizadas, pois tinham seu sentido capturado nas malhas do secular repertório eclesiástico (Carvalho, 2004, p. 95). 
DOI: https://doi.org/10.20396/zet.v27i0.8654185

Como procuramos explicar, a escolha das obras se deu em função dos critérios adotados por meio das descobertas que fizemos no contato com a BPAL. Sendo assim, ressaltamos, mas uma vez, nosso entendimento da importância de se estabelecer a metodologia de trabalho adequada ao objeto estudado, a partir de seu conhecimento.

\section{Investigação das marcas de leitor}

Nosso propósito, neste artigo, foi discorrer sobre as escolhas metodológicas para o estudo de uma biblioteca pessoal. Desse modo, não nos dedicaremos, aqui, a expor uma análise do conteúdo das duas obras. Todavia, um dos aspectos observados merece especial atenção: a investigação das marcas de leitor.

Partindo do circuito das comunicações, proposto por Darnton (1990), para a nossa análise, podemos pensar como os aspectos editoriais definem e delimitam a produção de obras, ou seja, o que nos revelam acerca da intencionalidade de decisões tomadas por seus produtores, autores e editores, para atingir o seu leitor-padrão. Para desprendermos das obras esses aspectos, lançamos mão da análise de seus aspectos internos e contextuais.

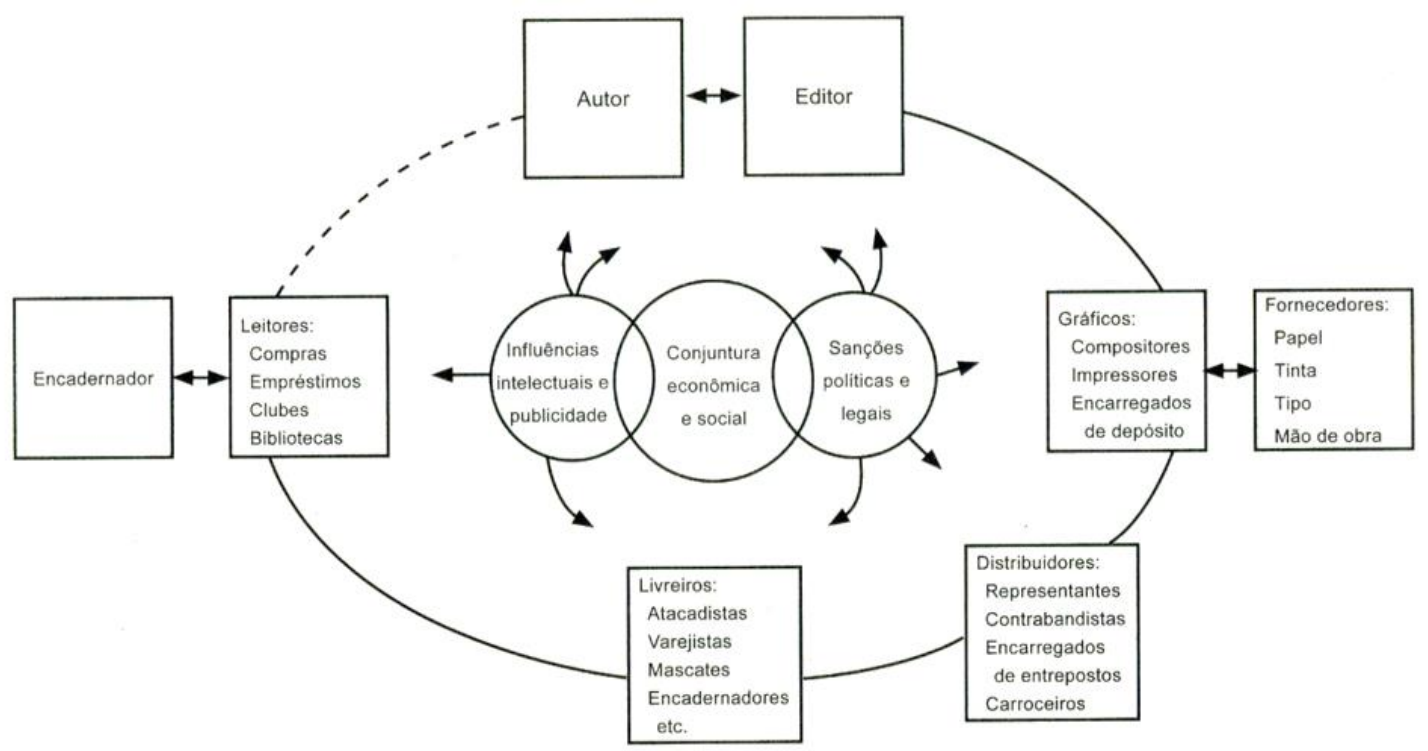

Figura 4 - $\mathrm{O}$ circuito das comunicações

Fonte: Darnton, 1990 (p. 113)

O esquema reproduzido acima propicia uma reflexão sobre a complexidade de produção do livro. Diferentemente do que se pode pensar, a autoria do livro é impactada por vários fatores: os ligados ao mercado (publicidade, vendagem, críticas), os relacionados ao contexto econômico e social, e os vinculados aos aspectos editoriais e políticos. Todos esses fatores têm repercussão no texto efetivamente publicado pelo autor, impondo-lhe parâmetros.

Em especial, ressaltamos um trecho em que Darnton (1990) enfatiza a importância de estabelecer um vínculo entre a obra e o leitor:

Temos centenas de listas de livros em bibliotecas, desde a Idade Média até o presente, numa quantidade que ninguém conseguia ler. Mas a maioria de nós concordaria que o catálogo de uma biblioteca particular pode servir como perfil de um leitor, mesmo que não leiamos todos os livros que possuímos e leiamos muitos livros que nunca 
DOI: https://doi.org/10.20396/zet.v27i0.8654185

compraremos. Examinar o catálogo da biblioteca de Monticello é inspecionar os materiais do cérebro de Jefferson. E o estudo das bibliotecas particulares tem a vantagem de ligar o "quê" com o "quem" da leitura (Darnton, 1990, p. 90, grifo nosso).

Existe, claramente, no nosso trabalho, a intencionalidade de se estabelecer uma compreensão das formas de leitura que possibilitaram a circulação do ideário pedagógico incutido nas páginas dos livros. No entanto, essa apropriação não é facilmente verificável.

Buscando compreender como a leitora Alda Lodi se relacionou com as obras, lançamos mão do estudo das marcas de leitor. Encaramos uma biblioteca pessoal não como a expressão da totalidade das vivências, concepções e experiências de um indivíduo, mas como uma amostra de referências do que ele tomou emprestado para a sua formação, do que ele internalizou, do que passou a integrar o seu capital cultural. Nesse sentido, a presença das marcas de leitor não apenas nos fornece indícios de que o livro foi efetivamente lido por Alda Lodi, mas também pode nos dizer como a leitora interagiu com seu conteúdo.

Porém, advertimos que na mobilização de marcas de leitor é necessário cuidado, pois elas podem ter sido produzidas não para evidenciar a adesão a ideias, mas apenas como estratégias de leitura. Por isso, também realizamos um cruzamento de dados com outras fontes, como cadernos de alunas e a agenda mantida pela professora durante sua estadia em Nova Iorque.

A análise das marcas de leitor nos deu pistas para compreender alguns casos em que a professora Alda Lodi se apropriou da leitura das duas obras. Enfatizaremos, nos próximos parágrafos, algumas das análises que realizamos por meio das marcas de leitor presentes na obra The New Methods in Arithmetic, de Edward Lee Thorndike.

A primeira marca de leitor encontrada no interior da obra foi verificada no capítulo IRealidade, na seção "Problemas genuínos". Nela, está marcado um parágrafo em que o autor exemplifica suas considerações.

Thorndike inicia o texto criticando os velhos métodos por autorizar o professor a propor qualquer tipo de problema, mesmo que ele não seja um problema real, do mundo real. Em contraposição, o autor afirma:

Os métodos mais novos estabelecem um padrão mais alto na seleção e construção de problemas, exigindo não apenas que eles deem ao aluno a oportunidade de pensar e aplicar conhecimento aritmético, mas também que o ensinem a pensar em aplicar a aritmética a situações que a vida pode oferecer, de maneiras úteis e razoáveis, e assim estimar a aritmética não apenas como um bom jogo para a mente, mas também como um ajudante substancial no trabalho da vida ${ }^{12}$ (Thorndike, 1926, p. 5).

A marca de leitor está presente em todo o parágrafo abaixo, que exemplifica a diferença na elaboração de problemas segundo as duas concepções contrapostas pelo autor.

\footnotetext{
${ }^{12}$ The newer methods set a higher standard in the selection and construction of problems, requiring not only that they give the pupil an opportunity to think and to apply arithmetical knowledge, but also that they teach him to think and to apply arithmetic to situations such as life may offer, in useful and reasonable ways, and so to esteem arithmetic not only as a good game for the mind, but also as a substantial helper in life's work.
} 
DOI: https://doi.org/10.20396/zet.v27i0.8654185

“A 3 centavos cada, qual será o custo de 4 dúzias de laranjas?" Demanda $4 \times 12 \times 3$, mas o preço por dúzia provavelmente seria inferior a 12 vezes 3 . Os métodos mais recentes substituiriam isso por um problema genuíno ou o alterariam para: "Um menino recebe 3 centavos por caixa para colher bagas. Quanto ele receberia por colher 4 dúzias de caixas?"13 (Thorndike, 1926, p. 6).

O trecho que foi assinalado na obra é representativo pois, assim como proposto por vários autores do movimento da Escola Nova, enfatiza a noção de que o conteúdo matemático deve ser voltado para a vida dos alunos, suas realidades e experiências.

Outra marca de leitor, no interior da obra, está na página 243, na seção "A Division Ladder", do capítulo XIII - Testes e exames. Essa marca é a palavra "série", escrita ao lado do título da seção, em que é exibido um exemplo com onze passos ou degraus para que o aluno avance no aprendizado das divisões. $\mathrm{O}$ autor defende, nesse trecho, que os problemas sejam graduados, possibilitando o avanço progressivo dos alunos. $\mathrm{O}$ trecho subsidia ao professor um instrumento para a montagem de listas de exercícios.

Thorndike (1926) argumenta:

A organização em uma série graduada por dificuldades tem várias vantagens. $\mathrm{O}$ aluno fica confiante no início e trabalha com uma atitude melhor. Ele tem cinco chances em cada grau de dificuldade de modo que o exame seja reconhecidamente justo e que o professor possa rapidamente distinguir falta de conhecimento no processo de descuido $^{14}$ (p. 244).

Além das marcas identificadas na obra, buscamos realizar cruzamentos entre os dados levantados e os documentos disponíveis no acervo de Alda Lodi. É interessante dar atenção a alguns trechos de um relatório, produzido no final de 1929, em que a professora apresenta suas atividades desde o retorno dos Estados Unidos.

O primeiro trecho diz respeito à finalidade da aritmética e parte dele é muito próxima do início do livro do autor norte-americano. Reproduzimos, primeiramente, o trecho da obra de Thorndike.

Os métodos mais antigos ensinavam aritmética pela aritmética, independentemente das necessidades da vida. Os métodos mais recentes enfatizam os processos que a vida exigirá e os problemas que a vida oferecerá ${ }^{15}$ (Thorndike, 1926, p. viii).

Alda Lodi escreveu em seu relatório:

Como Arith. não deve ser ensinada com o fim da arith. exclusivamente, á parte das necessidades da vida, sem atender ás sit. reaes que a creança encontra, mas sim a

\footnotetext{
13 "At 3 cents apiece what will be the cost of 4 dozen oranges?" calls for $4 \times 12 \times 3$, but the price per dozen would probably be less than 12 times 3 . The newer methods would replace this by a genuine problem or amend it to: "A boy is paid 3 cents per box for picking berries. How much is he paid for picking 4 dozen boxes?"

${ }^{14}$ The arrangement in a graded series by difficulty has several advantages. The pupil is given confidence at the beginning and works with a better atitude. He has five chances at each degree of difficulty so that the examination is admittedly fair and so that the teacher can quickly distinguish lack of knowledge of the process from carelessness.

15 The older methods taught arithmetic for arithmetic's sake, regardless of the needs of life. The newer methods emphasize the processes which life will require and the problems which life will offer.
} 
DOI: https://doi.org/10.20396/zet.v27i0.8654185

ajudal-a a estimar, a medir, a comparar, a calcular, a tornal-a socialmente efficiente no manejo das sit. numericas, entendemos iniciar nosso curso discutindo a creança e o programma escolar (Lodi, 1929, p. 1).

Como se constata facilmente, esses dois textos são extremamente parecidos, mostrando claramente uma adesão da leitora às ideias difundidas na obra de Thorndike.

No parágrafo seguinte do relatório, Lodi (1929) diz que se deve trabalhar com “o programma adaptado ao aprendiz e não este ao programma" (p. 1). Essa concepção é muito próxima à defendida por Thorndike e também evidencia que a professora concebia um ensino centrado no aluno.

Por fim, destacamos a seguinte reflexão de Lodi (1929):

Si Educação é preparo do individuo para viver mais efficientemente na sociedade, a Escola deve ser vida. Não são poucos os conhecimentos que adquirimos na infancia e no curso secundario e que por falta de applicação pouco duraram, ficando delles apenas a lembrança, ás vezes amarga, da energia e tempo gastos inutilmente. Assim, na pratica, quantas vezes encontramos frações como 15/67? Como 180/360? E no entanto são numeros que nos causam serias difficuldades na escola. E ainda hoje delles estão eivadas muitas das nossas Arithmeticas (p. 3, grifos da autora).

Nesse trecho, identificamos dois aspectos em sintonia com as ideias de Thorndike em seu livro. $\mathrm{O}$ primeiro se refere à necessidade de a escola ser voltada para a vida do educando e o segundo à necessidade de se aproximar as questões trabalhadas da realidade dos estudantes.

\section{Considerações Finais}

Gostaríamos de ressaltar que a opção que fizemos, de a partir do objeto definir os caminhos metodológicos a serem adotados na pesquisa, nos pareceu muito adequada para o estudo da BPAL. Definir a priori um conjunto de procedimentos em relação a um objeto de pesquisa poderia acarretar a não percepção de alguns nuances da biblioteca. Dessa forma, na experiência que desenvolvemos ao investigar a biblioteca de Alda Lodi, pudemos constatar que um conhecimento inicial das obras fundamentou a realização dos movimentos metodológicos aqui discutidos.

As marcas de leitor deixadas em boa parte das obras indicam algumas interações professora Alda Lodi teve com os livros e nos possibilitaram avançar na compreensão de como uma professora distante temporalmente de nós se apropriou das obras. Tal entendimento nos parece muito relevante para investigar as apropriações e proximidades da professora com o movimento escolanovista. De fato, essas marcas favorecem nosso entendimento das interações da leitora com sua biblioteca e nossa compreensão sobre sua atuação na formação de professoras em Metodologia da Aritmética na Escola de Aperfeiçoamento.

Finalizando, reiteramos nossa intenção ao elaborar este texto: com a divulgação e as considerações sobre os movimentos metodológicos de uma investigação sobre uma biblioteca, inspirar outras pesquisas possíveis no campo da História da Educação Matemática. 


\section{Referências}

DOI: https://doi.org/10.20396/zet.v27i0.8654185

Amorim, B. D. (2018). Indicações metodológicas para o ensino da Matemática presentes em livros que circularam em minas gerais na primeira metade do século XX: um estudo da biblioteca pessoal da Professora Alda Lodi. Dissertação de Mestrado. Belo Horizonte: Universidade Federal de Minas Gerais. Retirado em 02 de dezembro, 2018, de http://www.bibliotecadigital.ufmg.br/dspace/handle/1843/BUOS-B5TK2J.

Backheuser, E. (1933). A aritmética na "Escola Nova" (a nova didática da aritmética). Rio de Janeiro: Livraria Católica.

Carvalho, M. M. C. de. (2004). A Escola Nova no Brasil: uma perspectiva de estudo. Educação em Questão, 21(7), 90-98. Disponível em: https://periodicos.ufrn.br/educacaoemquestao/article/view/8382/0.

Darnton, R. (1990). O beijo de Lamourette: mídia, cultura e revolução. Tradução de Denise Bottmann. São Paulo: Companhia das Letras.

Fonseca, N. M. L. (2010). Alda Lodi, entre Belo Horizonte e Nova Iorque: um estudo sobre formação e atuação docentes 1912-1932. Dissertação de Mestrado em Educação. Belo Horizonte: Universidade Federal de Minas Gerais. Retirado em 09 de agosto, 2018, de http://www.bibliotecadigital.ufmg.br/dspace/handle/1843/FAEC-8MRFRE.

Galvão, A. M. O., \& Oliveira, P. J. P. (2007). Objetos e Práticas de leitura de um "novo letrado": Estudo de um percurso individual no século XX. In A. M. O. Galvão. História da Cultura Escrita: séculos XIX e XX. Belo Horizonte: Autêntica.

Garnica, A. V. M. História Oral em educação matemática: um panorama sobre pressupostos e exercícios de pesquisa. História Oral, 18(2), 35-53. Disponível em: http://revista.historiaoral.org.br/index.php?journal=rho\&page=article\&op=view\&path $\% 5$ $\mathrm{B} \% 5 \mathrm{D}=559$ \&path\%5B $\% 5 \mathrm{D}=$ pdf.

Genette, G. (2009). Paratextos editoriais. Cotia: Ateliê Editorial.

Houaiss, A., Villar, M. de S., \& Franco, F. M. de M. (2009). Dicionário Houaiss da língua portuguesa. Rio de Janeiro: Objetiva.

Lodi, A. (1929). [Relato de atividades desenvolvidas nos três primeiros meses como docente da Escola de Aperfeiçoamento]. Belo Horizonte: não publicado.

Medeiros, V. M. (2013). O liberalismo e as proposições de John Dewey para a Educação Elementar. Dissertação de Mestrado. Cascavel: Universidade Estadual do Oeste do Paraná, UNIOESTE. Retirado em 02 de dezembro, 2018, de http://tede.unioeste.br/bitstream/tede/3639/5/Verenice\%20Mioranza\%20De\%20Medeiro s.pdf.

Peixoto, A. M. C. (2003). Uma nova era na escola primária mineira. A Reforma Francisco Campos e Mario Casasanta. In: M. C. Leal \& M. A. L. Pimentel (Orgs.), História e Memória da Escola Nova. São Paulo: Edições Loyola. 
DOI: https://doi.org/10.20396/zet.v27i0.8654185

Rabelo, R. S. (2016). Destinos e Trajetos: Edward Lee Thorndike e John Dewey na formação matemática do professor primário no Brasil (1920-1960). Tese de Doutorado em Educação. São Paulo: Universidade de São Paulo. Retirado em 09 de agosto, 2018, de https://repositorio.ufsc.br/handle/123456789/164112.

Reis, D. A. F. (2014). História da formação de professores de Matemática para os anos iniciais em Minas Gerais: Um estudo a partir do acervo de Alda Lodi (1927 a 1950). Tese de Doutorado em Educação. Belo Horizonte: Universidade Federal de Minas Gerais. Retirado em 09 de agosto, 2018, de http://www.bibliotecadigital.ufmg.br/dspace/handle/1843/BUOS-9LVP8T.

Santos, I. B. (2006). Edward Lee Thorndike e a conformação de um novo padrão pedagógico para o ensino de matemática (Estados Unidos, primeiras décadas do século XX). Tese de Doutorado em Educação. São Paulo: Pontifícia Universidade Católica de São Paulo. Retirado em 09 de agosto, 2018, de https://sapientia.pucsp.br/handle/handle/10487.

Thorndike, E. L. (1926). The new methods in arithmetic. New York: Rand McNally \& Company.

Veiga, C. G. (2007). História da Educação. São Paulo: Ática. 